\title{
Reduced Actuator Set for Pressure Control and Thrust Distribution for Multinozzle Propulsion Systems
}

\author{
Yeerang Lim, ${ }^{1}$ Jaecheong Lee, ${ }^{2}$ Hyochoong Bang, ${ }^{1}$ Hwanil Huh, ${ }^{2}$ and Hosung Lee ${ }^{3}$ \\ ${ }^{1}$ Korea Advanced Institute of Science and Technology, Daejeon 34141, Republic of Korea \\ ${ }^{2}$ Chungnam National University, Daejeon 34134, Republic of Korea \\ ${ }^{3}$ Agency for Defense Development, Daejeon 34186, Republic of Korea \\ Correspondence should be addressed to Yeerang Lim; yrlim@ascl.kaist.ac.kr
}

Received 28 November 2016; Revised 13 March 2017; Accepted 20 March 2017; Published 8 May 2017

Academic Editor: Mahmut Reyhanoglu

Copyright (C) 2017 Yeerang Lim et al. This is an open access article distributed under the Creative Commons Attribution License, which permits unrestricted use, distribution, and reproduction in any medium, provided the original work is properly cited.

\begin{abstract}
This study investigated an approach to reduce the number of actuators used for internal pressure control and thruster allocation in a multinozzle solid propulsion system. In the proposed design, the throat areas of four divert nozzles are controlled by only three actuators, and chamber pressure maintenance and thrust distribution are achieved by controlling the throat areas. Using the proposed actuator set, thrust allocation can be accomplished in a more efficient way than when independent actuators are employed for each nozzle.
\end{abstract}

\section{Introduction}

Solid propulsion systems have been widely studied and applied in diverse applications, because their design is simple and they have a shorter response time than liquid propulsion systems. These simple systems can also be expanded: the variable thrust solid propulsion system (VTSPS), for example, is equipped with multiple thrust nozzles on a single combustion chamber. The multiple nozzles enable the single chamber to execute agile divert maneuvers, as well as maintain attitude control.

In the VTSPS, the thrust of the nozzles is controlled by changing the nozzle throat area using a pintle actuator. Since all the nozzles share a single combustion chamber, the throat area of each nozzle affects the entire chamber's throat area, which is directly connected to the chamber's pressure. Therefore, the key to VTSPS control lies in controlling the throat area and simultaneously considering chamber pressure control and thrust distribution [1]. In other words, the control input to the throat area of each nozzle should satisfy the constraint for pressure maintenance. Lee et al. described an approach and introduced a thrust allocation algorithm to maximize thrust output efficiency [2]. Concentrating on the chamber pressure, Bergmans and Di Salvo established a pressure differential equation for the combustion chamber and applied a feedback control algorithm [3]. Lee et al. introduced an adaptive controller based on feedback linearization [4-6] to deal with system uncertainties and time-varying parameters such as chamber free volume and performed an associated stability analysis.

One simple way of controlling a solid propulsion system is to control all of the nozzles independently. The conventional variable thrust solid propulsion system has four divert nozzles and has four main actuators to manipulate the four nozzle throat areas. Typically there are six additional subnozzles for decoupled attitude control, as shown in Figure 2. This approach is intuitive and allows each nozzle throat area to be controlled independently. Nevertheless, this design is relatively inefficient when the associated system mass budget is considered. If the same system control performance could be achieved with fewer or smaller actuators, the system mass could be reduced while also enhancing maneuvering performance.

This paper proposes a novel pintle actuator mechanism for four divert control system (DCS) nozzles, which has three actuator components, rather than the conventional four. The number of actuators can be reduced by interconnecting each of the actuators using an incompressible fluid. For divert 


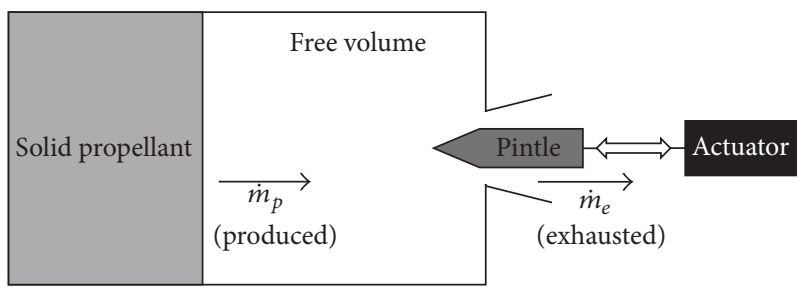

FIGURE 1: Variable thrust solid propulsion system (VTSPS) with a pintle valve.

maneuver in the $y-z$ body plane, which is perpendicular to the axial $x$ direction, two actuators handle bidirectional thrusts, respectively. Because they share the incompressible fluid in the bottom of each actuator, the uncontrolled actuators are automatically moved backward when one or two of the pintle actuators are moved by a control command. In this way, the ratio of total nozzle throat area to chamber pressure will remain constant when the nozzle throat area is varied linearly by the pintle actuator movement. This means the thrusts can be distributed under controlled pressure. While it is necessary to employ a thrust distribution algorithm when each pintle is controlled independently, because there are multiple ways to distribute thrust, with the linear throat area change strategy proposed in this study the most efficient distribution algorithm is achieved naturally by the incompressible fluid.

The role of the extra actuator is to manage pressure control without generating any thrust, by pushing or pulling all four DCS pintles with the same amount of displacement by changing the quantity of incompressible fluid. As mentioned above, by downsizing the number of actuators, this approach can reduce overall system mass.

This paper has three sections. The basic model of the variable thrust solid propulsion system is derived in the second section. In the third section, the concept of the reduced actuator set for managing chamber pressure control and DCS thrust distribution is proposed. Finally, the proposed actuator mechanism idea is verified with simulation studies.

\section{Variable Thrust Solid Propulsion System}

A variable thrust solid propulsion system (VTSPS) includes a chamber which contains a solid-propellant. Figure 1 shows the schematic of the combustion chamber. Since the free volume inside the chamber tends to change with propellant combustion, the chamber pressure is controlled by varying the nozzle throat area. The throat area $A_{t}$ can be varied via a pintle actuator.

The $x$-axis of the VTSPS in the body frame defines the velocity direction of the vehicle. The center of mass is the origin of the body frame coordinate system. A traditional VTSPS has ten nozzles in total. Four primary nozzles, $D_{1}, D_{2}$, $D_{3}$, and $D_{4}$, are located on the $y-z$ plane, which is perpendicular to the velocity direction. These primary nozzles are not related to thrust for movement in the $x$-axis direction: the primary nozzles control position in the orthogonal plane only. Another six small nozzles, $A_{i}(i=1 \cdots 6)$ are employed for attitude control. Because the power capacity of the primary nozzles is much larger than the attitude nozzles, the primary nozzles manage chamber pressure control as well as axial thrust.

Since the primary nozzles control both chamber pressure and axial thrust, the pintle control input should be computed to simultaneously maintain pressure and thrust distribution after first determining the ACS nozzles' control input.

Each DCS nozzle is controlled by the combination of independent pintle actuators.

$$
\begin{aligned}
F_{\text {sys }}-\sum_{j=1}^{6} F_{A_{j}} & =F_{D_{\text {sum }}}=\sum_{i=1}^{4} F_{D_{i}}, \\
F_{y} & =F_{D_{1}}-F_{D_{2}}, \\
F_{z} & =F_{D_{3}}-F_{D_{4}}
\end{aligned}
$$

with

$$
0 \leq F_{D_{i}} \leq F_{D_{\text {sum }}} .
$$

The entire control loop including pressure control and thrust distribution is summarized in Figure 3.

The following subsections discuss the chamber pressure control algorithm and the efficient thrust distribution approach.

2.1. Internal Ballistics Model and Chamber Pressure Control $[7,8]$. The thrust capacity of the VTSPS depends on the chamber pressure $P_{c}$ and the total nozzle throat area $A_{t}$ such that

$$
F=C_{f} A_{t} P_{c},
$$

where $C_{f}$ represents a thrust coefficient defined as

$$
\begin{aligned}
C_{f}= & \sqrt{\frac{2 \gamma^{2}}{\gamma-1}\left\{\frac{2}{\gamma+1}^{(\gamma+1) /(\gamma-1)}\left[1-\left(\frac{P_{e}}{P_{c}}\right)^{(\gamma-1) / \gamma}\right]\right\}} \\
& +\left(\frac{P_{e}-P_{a}}{P_{c}}\right) \frac{A_{e}}{A_{t}}
\end{aligned}
$$

A chamber pressure differential equation can be derived from the laws of mass conservation.

$$
\dot{m}=\frac{d}{d t}\left(\rho_{c} V_{c}\right)+\dot{m}_{e}=\frac{d}{d t}\left(\rho_{c} V_{c}\right)+A_{t} U_{t} \rho_{t} .
$$

The first and second parts of the equation above can be derived further.

$$
\begin{aligned}
\frac{d}{d t}\left(\rho_{c} V_{c}\right) & =\frac{d}{d t}\left(\frac{P_{c}}{R T_{c}} \times V_{c}\right) \\
& =\frac{1}{R T_{c}}\left(P_{c} \frac{d V_{c}}{d t}+V_{c} \frac{d P_{c}}{d t}\right), \\
A_{t} U_{t} \rho_{t} & =\frac{P_{t}}{R T_{t}} \times A_{t} \times M_{t} \sqrt{k R T_{t}},
\end{aligned}
$$



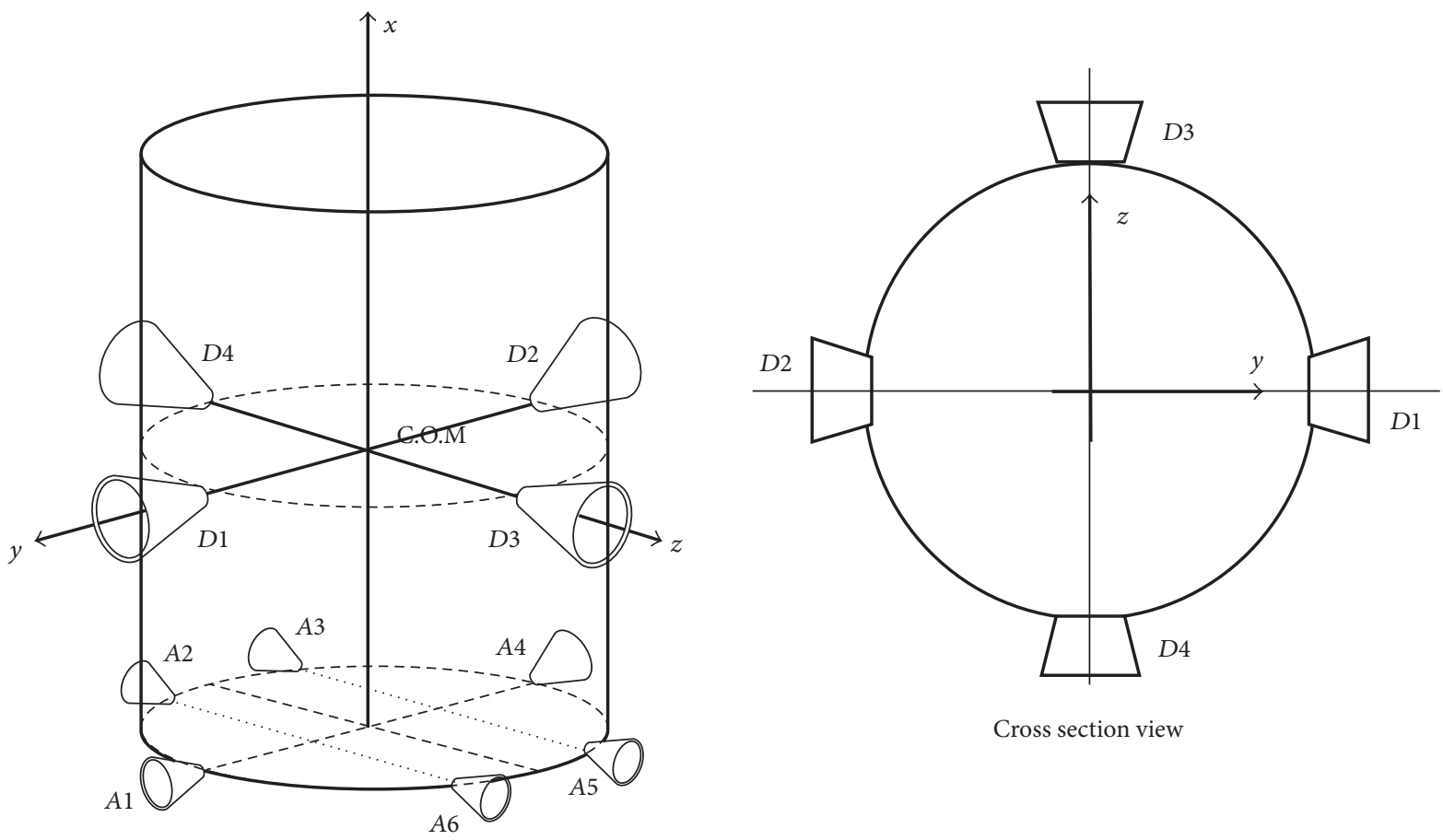

Figure 2: Thruster set for divert and attitude control.

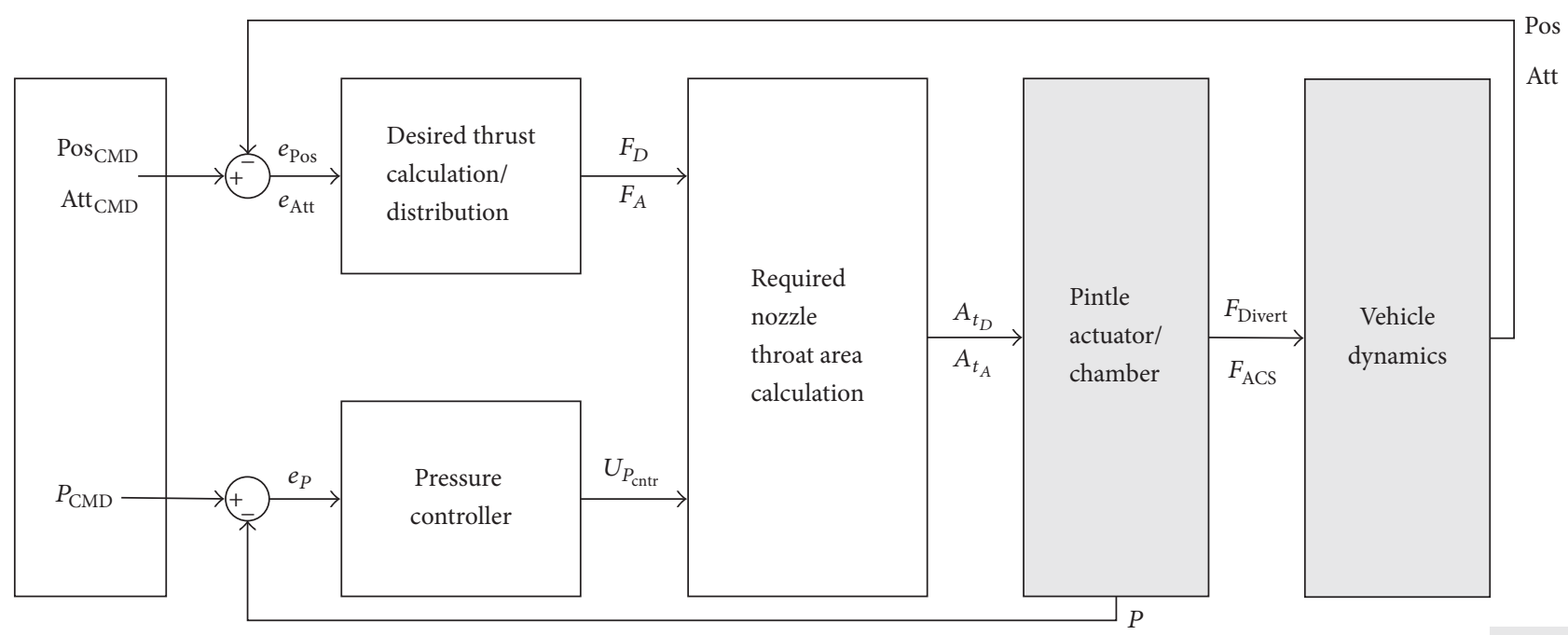

Figure 3: Pintle actuator control loop.

where $T_{c}$ is the chamber gas temperature, $P_{t}$ is the pressure at the nozzle throat, and $M_{t}$ represents the Mach number of the exhausted gas at the nozzle throat. Using those two equations, a pressure differential equation can be derived such that

$$
\frac{d P_{c}}{d t}=\frac{A_{b} r \rho_{p} R T_{c}}{V_{c}}-\frac{P_{t} A_{t} M_{t}}{V_{c}} \sqrt{k R T_{t}}-\frac{P_{c}}{V_{c}} \frac{d V_{c}}{d t} .
$$

With the nozzle chocked, the mass conservation equation can be derived in a different way.

$$
\dot{m}=\frac{d}{d t}\left(\rho_{c} V_{c}\right)+A_{t} P_{c} \sqrt{\frac{k}{R T_{c}}\left(\frac{2}{k+1}\right)^{(k+1) /(k-1)}} .
$$

Furthermore, the pressure differential equation, which is the internal ballistic model, can be derived.

$$
\begin{aligned}
\frac{d P_{c}}{d t}= & \frac{R T_{c} A_{b} r \rho_{p}}{V_{c}} \\
& -\frac{R T_{c} A_{t} P_{c}}{V_{c}} \sqrt{\frac{k}{R T_{c}}\left(\frac{2}{k+1}\right)^{(k+1) /(k-1)}}-\frac{P_{c}}{V_{c}} \frac{d V_{c}}{d t} .
\end{aligned}
$$

Therefore, the chamber inner pressure is determined from the combustion of gas free volume and the throat area. 


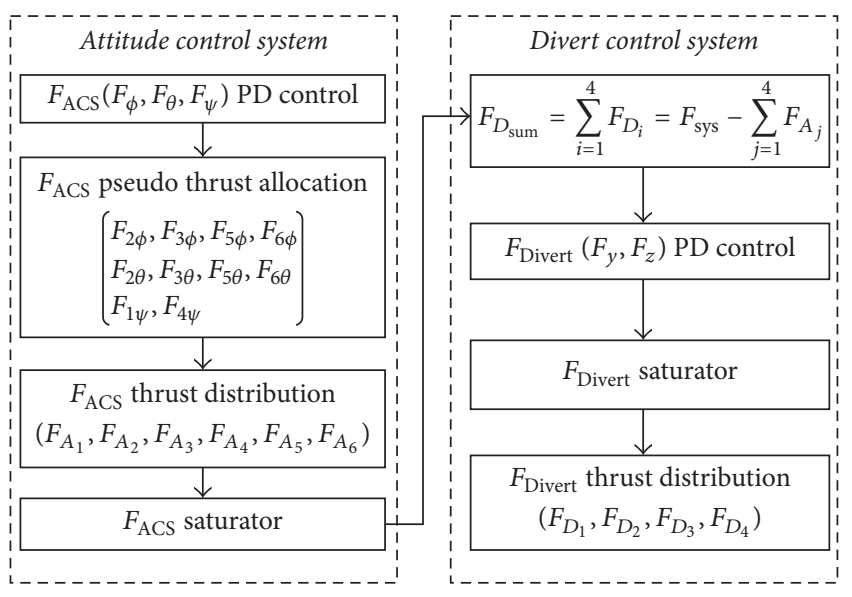

FIgURE 4: Thrust distribution logic flow chart.

2.2. Thrust Distribution. As mentioned earlier, thrust for attitude control is determined first, since the ACS nozzles are much smaller than the DCS nozzles. After determining the ACS control input value, the DCS nozzle thrust distribution is performed with the new thrust limit $F_{D_{\text {sum }}}=F_{\text {sum }}-$ $\sum F_{\text {ACS }}$. The desired thrust is calculated using a simple PD (proportional plus derivative) controller. Detailed thrust distribution algorithm is shown in Figure 4.

When the DCS thrust capacity $F_{D_{\text {sum }}}$ is given, a simple way to distribute thrust for the two $y / z$ axes is to divide the thrust capacity in half, as $F / 2$ for each axis, and then distribute the thrust as well. The weakness of this approach lies in efficiency. Since it divides capacity before considering the actual thrust, we can only use half of the thrust capacity even when the desired thrust is aligned to one axis only.

The other approach is to distribute thrust based on best efficiency. When the available maximum DCS thrust value is determined to be $F_{D_{\text {sum }}}$ and the desired thrust direction $\theta$ is given, then the solution to obtain maximum thrust usage will be the point of intersection between the tangent line with $\theta$ and the square boundary of $\left|F_{y}\right|+\left|F_{z}\right|<F_{D_{\text {sum }}}$ in Figure 5. If the desired thrust exceeds the thrust limit, $F_{y}$ and $F_{z}$ should be normalized as below.

$$
\begin{aligned}
& F_{y}=F_{D_{\text {sum }}} \frac{F_{y}}{\sqrt{F_{y}{ }^{2}+F_{z}^{2}}}, \\
& F_{z}=F_{D_{\text {sum }}} \frac{F_{z}}{\sqrt{F_{y}^{2}+F_{z}^{2}}} .
\end{aligned}
$$

The final DCS thrust distribution should be calculated as shown in Table 1.

Since there are four control variables $F_{D_{1}} \cdots F_{D_{4}}$ and three equality constraints as (1), there are more than one thrust combinations available. To get a unique solution, an optimization problem as (11) can be suggested to minimize the pintle maneuver. Because of three equality constraints,

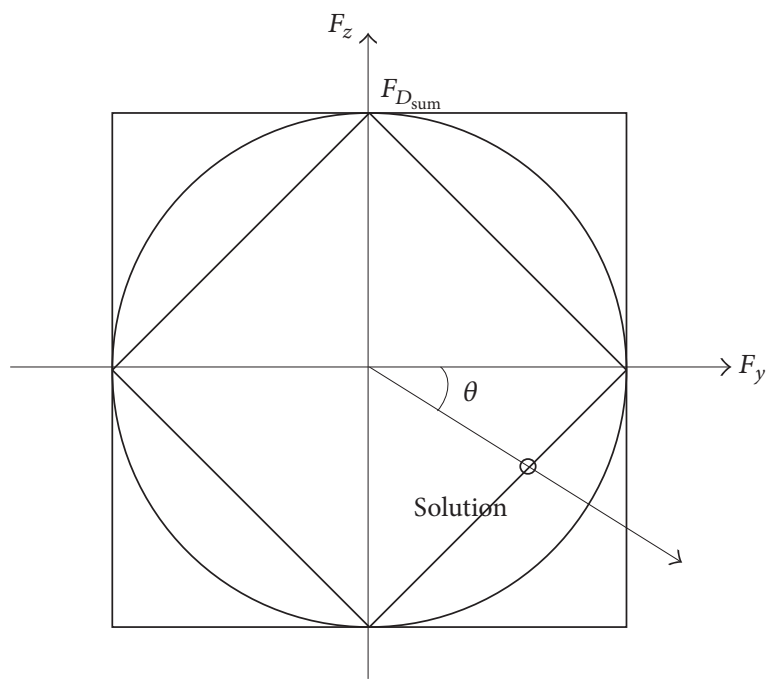

FIGURE 5: DCS thrust solution with maximized output efficiency.

four DCS thrusts can be expressed as a function of one thrust. The solution can be derived from $\partial J / \partial F_{D_{i}}=0$.

$$
\begin{array}{ll}
J=\min & \sum_{i=1}^{4}\left(F_{D_{i}}-F_{\mathrm{eq}}\right)^{2}, \\
\text { where } \quad & F_{D_{1}}-F_{D_{2}}=F_{y}, \\
& F_{D_{3}}-F_{D_{4}}=F_{z}, \\
& F_{D_{1}}+F_{D_{2}}+F_{D_{3}}+F_{D_{4}}=F_{D_{\text {sum }}}, \\
& F_{\text {eq }}=\frac{F_{D_{\text {sum }}}}{4} .
\end{array}
$$

\section{Reduced Pintle Actuator Mechanism for DCS Nozzles}

Since there are four DCS nozzles, as shown in Figure 2, the most direct approach would be to command the four actuators by controlling each nozzle throat area independently. Let us assume that each pintle is moved by a dedicated piston actuator. The piston will move when there is a pressure difference between the upper/lower sides of the piston itself.

Alternatively, the proposed pintle actuator, which is more compact, has a pair of ball valves for controlling movement in the $y / z$ directions, which always move together. For example, if the $y$-axis actuator moves toward the $+y$ direction, this will simultaneously reduce the $+y$ nozzle throat area and enlarge the $-y$ nozzle throat area, because the movement of the $+y$ ball valve toward the nozzle moves the $-y$ ball valve away from the nozzle.

The detailed mechanism for controlling the piston is explored here. The upper part of each piston consists of a chamber and two flow channels, the inlet and the outlet. The area of the inlet is kept constant, while the outlet area is varied by moving a ball valve toward or away from the outlet as 
TABLE 1: Maximum force available based on saturation limit [2].

\begin{tabular}{lcccc}
\hline Force & (1) & Quadrant & & \\
& $\frac{F_{D_{\text {sum }}}}{1+\tan \theta}$ & $\frac{F_{D_{\text {sum }}}}{-1+\tan \theta}$ & $\frac{-F_{D_{\text {sum }}}}{1+\tan \theta}$ & $-F_{D_{\text {sum }}}$ \\
\hline$F_{y}$ & $\frac{F_{D_{\text {sum }}}}{1+\tan \theta} \tan \theta$ & $\frac{F_{D_{\text {sum }}}}{-1+\tan \theta} \tan \theta$ & $\frac{-F_{D_{\text {sum }}}}{1+\tan \theta} \tan \theta$ & $\frac{-F_{D_{\text {sum }}}}{-\tan \theta} \tan \theta$ \\
$F_{z}$ & & & $-1+\tan \theta$ & \\
\hline
\end{tabular}

Figure 7. The movement of the ball valve allows flow from the outlet to be controlled under a pressure difference. If the ball valve is moved away from the outlet, the outlet area will become the same as the inlet area, which is kept constant.

$$
A_{\text {out }}=A_{\text {out }}\left(x_{v}\right)= \begin{cases}A_{0}\left(1-x_{v}\right) & x_{v} \geq 0 \\ A_{0} & x_{v}<0 .\end{cases}
$$

If the ball valve is in its neutral position, that is, $A_{\text {in }}=$ $A_{\text {out }}$, the amount of inlet flow and the output flow will be the same if the supply pressure $P_{s}$ and the return pressure $P_{r}$ are equal. There will be no pressure difference generated in this case.

$$
\begin{aligned}
Q_{\text {in }} & =C_{d} A_{\text {in }} \sqrt{\frac{\rho\left(P_{s}-P\right)}{2}}, \\
Q_{\text {out }} & =C_{d} A_{\text {out }} \sqrt{\frac{\rho\left(P-P_{r}\right)}{2}}, \\
\Delta Q & =Q_{\text {in }}-Q_{\text {out }}=0 \text { when } A_{\text {in }}=A_{\text {out }} .
\end{aligned}
$$

If the ball valve moves toward the outlet, a differential flow $\Delta Q$ will be generated even though no pressure difference exists, because the outlet area will be smaller than the inlet area, since the ball valve is now blocking the outlet area.

$$
\Delta Q=Q_{\text {in }}-Q_{\text {out }}>0 \quad \text { when } A_{\text {in }}>A_{\text {out }} .
$$

This flow difference will cause a change in the volume and the pressure in the upper part of the piston.

$$
\begin{aligned}
\Delta Q & =Q_{\text {in }}-Q_{\text {out }} \\
& =C_{d} A_{\text {in }} \sqrt{\frac{\rho\left(P_{s}-P\right)}{2}}-C_{d} A_{\text {out }} \sqrt{\frac{\rho\left(P-P_{r}\right)}{2}} \\
& =\frac{d V}{d t}+\frac{V}{\beta_{e}} \frac{d P}{d t} .
\end{aligned}
$$

When this pressure changes, the force applied to the piston area will push the piston backward.

$$
f=P \times A_{p} .
$$

If two ball valves on the same axis are connected to one actuator, one can imagine that the two outlet areas will

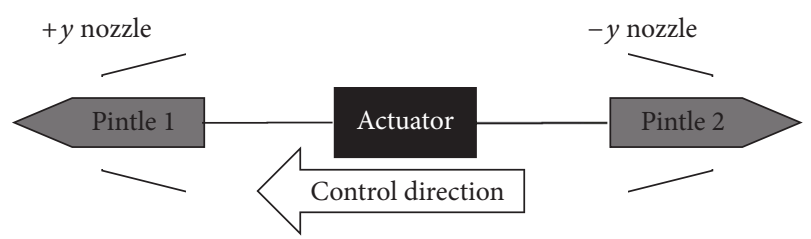

FIGURE 6: Schematic of an actuator linked to two pintles on the same axis.

be controlled together in a reciprocal way, as illustrated in Figure 6 . If the ball valves are initially in a neutral position and the actuator moves toward the $+y$ direction, as shown in Figure 8, the $+y$ outlet will be narrowed because the ball valve blocks the outlet area. At the same time, because the ball valve moves away from the $-y$ outlet, there is no change in that outlet, and no effect on the outlet area.

When the piston outlet area is smaller than the inlet area, additional fluid will be accumulated in the upper piston area. The additional fluid will push the piston in the opposite direction. This piston movement will apply pressure to the fluid in the lower piston area. As shown in Figure 9, since this fluid is also shared by the other piston, pushing the fluid will cause the other piston to move. That is, if one piston is controlled, the other piston is reciprocally controlled, automatically. If one actuator moves, one of the pistons is affected directly because the outlet area of the upper piston chamber becomes smaller. This will cause a differential pressure which forces the piston to move. The incompressible fluid will also be moved with the piston, and the fluid motion will push the other piston backward under the volume conservation principle. Then the pintle actuators will follow the movement of the pistons.

This mechanism can also be used to control thrust distribution, because if we intend to create movement in a certain direction it is necessary to reduce the thrust of one nozzle and produce greater thrust in the other nozzle on the same axis.

In the proposed design, there are two such actuators, which are each connected to a pair of ball valves. There should also be one additional valve actuator, to control the amount of incompressible fluid in the lower piston area of all the actuators. If the amount of fluid decreases, all four pistons will move outward, and they will be pushed inward if the fluid is increased. This will affect the total nozzle throat area, which is important for controlling the chamber pressure, although there will be no change in thrust, because all of the pistons 

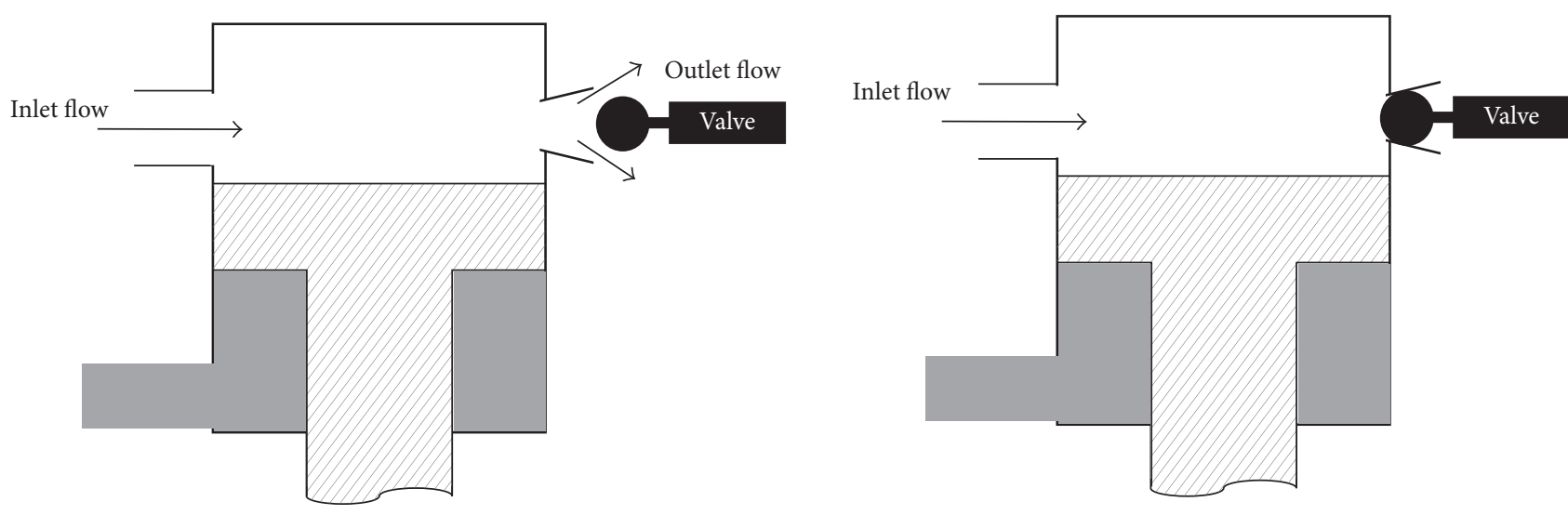

FIGURE 7: Piston control mechanism with ball valve.

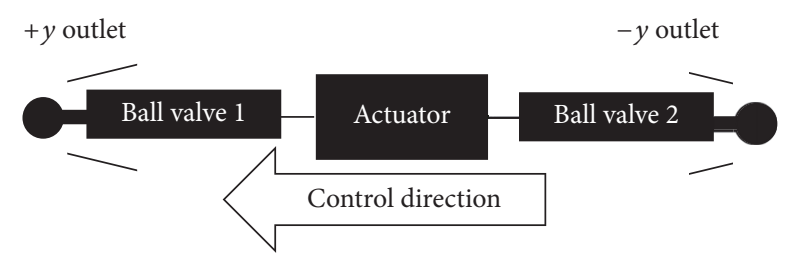

Figure 8: Actuator schematic linked to two ball valves on the same axis.

will have been moved in the same direction. Figure 10 shows the suggested system schematic.

If the nozzle throat area can be expressed as a linear function with respect to the pintle actuator displacement, the nozzle throat area can be controlled to meet the maximized DCS thrust efficiency, while maintaining pressure.

$$
\begin{aligned}
A_{t}= & A_{t}\left(X_{p}\right)=a x+b \\
& \text { where } X_{p}=\operatorname{pintle}(\text { piston }) \text { displacement } \\
\sum_{i=1}^{4} A_{t, i}= & \left(a X_{p, 1}+b\right)+3 \times\left(a \times\left(-\frac{1}{3} X_{p, 1}\right)+b\right) \\
= & 4 b \quad \text { when pintle } 1 \text { controlled, } \\
\sum_{i=1}^{4} A_{t, i}= & \left(a X_{p, 1}+b\right)+\left(a X_{p, 3}+b\right)+2 \\
& \times\left(a \times\left(-\frac{1}{2}\left(X_{p, 1}+X_{p, 3}\right)\right)+b\right)=4 b
\end{aligned}
$$

when pintle 1,3 controlled.

For the conventional VTSPS, degree of freedom for the divert maneuver is four, since there are four nozzles and related pintle actuators. And there are three constraints: one is to maintain the sum of the thrusters (which is equivalent to the chamber pressure control), and the other two are for the thrust requirement for $y / z$-axis, respectively. There will be more than one actuators maneuver combination
TABLE 2: Thrust distribution algorithm for the original VTSPS.

\begin{tabular}{ll}
\hline $\begin{array}{l}\text { Control } \\
\text { variables (4) }\end{array}$ & $x_{v_{1}}, x_{v_{2}}, x_{v_{3}}, x_{v_{4}}\left(F_{D_{1}}, F_{D_{2}}, F_{D_{3}}, F_{D_{4}}\right)$ \\
& $F_{D_{1}}-F_{D_{2}}=F_{y}$ \\
& $F_{D_{3}}-F_{D_{4}}=F_{z}$ \\
& $F_{D_{1}}+F_{D_{2}}+F_{D_{3}}+F_{D_{4}}=F_{D_{\text {sum }}}$ \\
& $F_{\text {eq }}=\frac{F_{D_{\text {sum }}}}{4}$ \\
& $0 \leq F_{D_{i}} \leq F_{D_{\text {sum }}}$ \\
& Additional optimization problem: \\
& $J=$ \\
& $\min \sum_{i=1}^{4}\left(F_{D_{i}}-F_{\text {eq }}\right)^{2}$ which means $\partial J / \partial F_{D_{i}}=$ \\
& 0 \\
& $F_{D_{1}}=\frac{1}{2}\left(F_{D_{\text {sum }}}+F_{y}-F_{z}\right)-F_{D_{4}}=F_{\text {eq }}+\frac{1}{2} F_{y}$ \\
& $F_{D_{2}}=\frac{1}{2}\left(F_{D_{\text {sum }}}-F_{y}+F_{z}\right)-F_{D_{4}}=F_{\text {eq }}-\frac{1}{2} F_{y}$ \\
& $F_{D_{3}}=F_{z}+F_{D_{4}}=F_{\text {eq }}+\frac{1}{2} F_{z}$ \\
& $F_{D_{4}}=\frac{1}{4}\left(F_{D_{\text {sum }}}-2 F_{z}\right)=F_{\text {eq }}-\frac{1}{2} F_{z}$ \\
\hline &
\end{tabular}

available, since degree of freedom is larger than the number of constraints. To get a unique solution, optimization problem as (11) suggested minimizing actuator maneuvers. Detailed solution can be derived as Table 2 .

For the reduced actuator system, there are still four thrusters available. The effect caused by the reduced actuator can be rewritten as an additional constraint as below, which makes the solution unique without an optimization problem. The solution is different from the conventional VTSPS's thrust combination, which means the thrust variation from $F_{\text {eq }}$ could be larger than the optimal solution. However, the resulting net thrust will be the same as before. Thrust distribution solution for the reduced system can be derived as Table 3.

Because all the thruster has the maximum limit $F_{D_{\text {sum }}}$ and the thrust combination could not exceed it, this does not mean that there will be performance degradation. Also, 


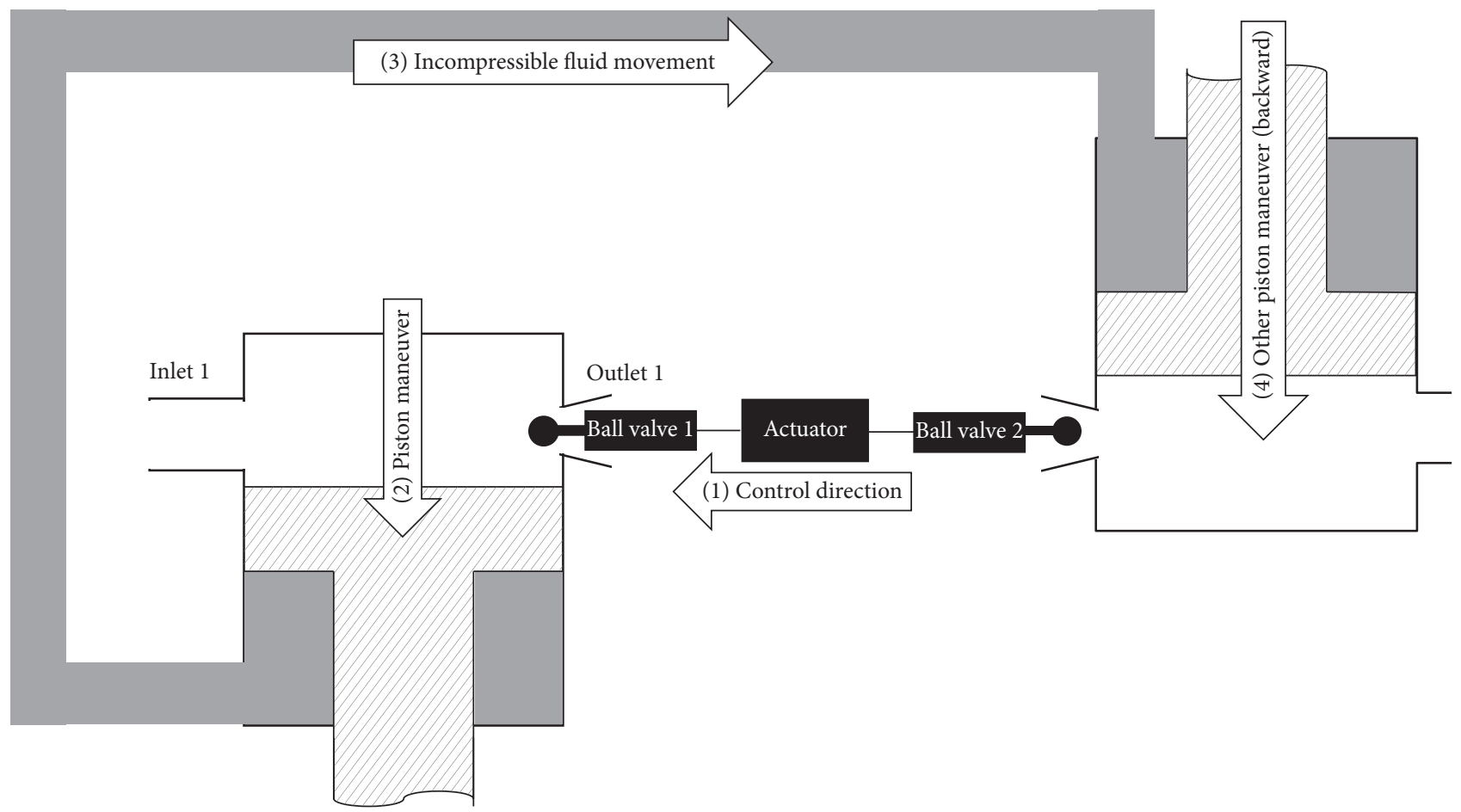

FIGURE 9: Schematic of actuator linked to two pintles on the same axis with dedicated pistons.

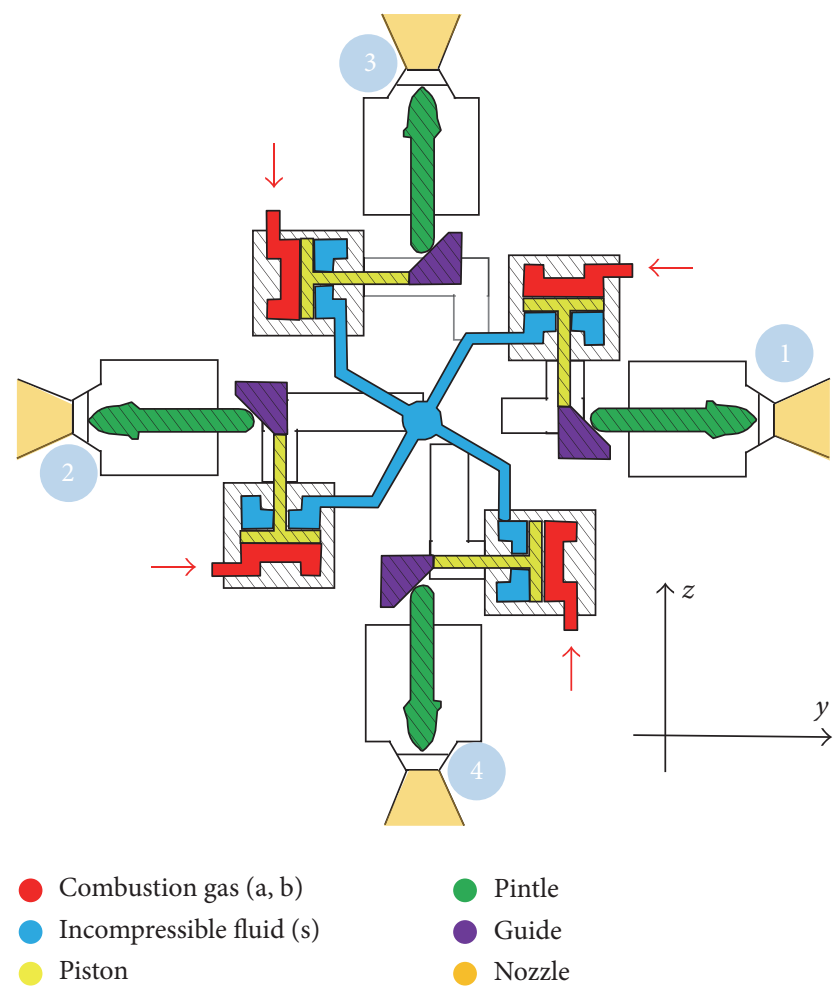

FIGURE 10: Schematic of the proposed pintle actuator.

efficiency of the proposed system cannot be compared easily to the conventional system, since the maneuver is optimized with respect to the equalized state only.
TABLE 3: Thrust distribution algorithm for the reduced actuator.

\begin{tabular}{ll}
\hline Control variables (3) & $x_{v_{y}}, x_{v_{z}}, x_{v_{P}}\left(F_{D_{1}}, F_{D_{2}}, F_{D_{3}}, F_{D_{4}}\right)$ \\
& $F_{D_{1}}-F_{D_{2}}=F_{y}$ \\
& $F_{D_{3}}-F_{D_{4}}=F_{z}$ \\
& $F_{D_{1}}+F_{D_{2}}+F_{D_{3}}+F_{D_{4}}=F_{D_{\text {sum }}}$ \\
& $F_{\text {eq }}=\frac{F_{D_{\text {sum }}}}{4}$ \\
& $0 \leq F_{D_{i}} \leq F_{D_{\text {sum }}}$ \\
& \\
& Since $F_{D_{2}}=F_{D_{3}}=F_{D_{4}}:$ \\
& $F_{y}=F_{D_{1}}-F_{D_{2}}$ \\
& $F_{z}=F_{D_{3}}-F_{D_{4}}=F_{D_{2}}-F_{D_{2}}=0$ \\
& $F_{D_{\text {sum }}}=F_{D_{1}}+F_{D_{2}}+F_{D_{3}}+F_{D_{4}}=F_{D_{1}}+3 F_{D_{2}}$ \\
& Therefore, \\
& $F_{D_{2}}=F_{D_{3}}=F_{D_{4}}=F_{\text {eq }}-\frac{1}{4} F_{y}$ \\
& $F_{D_{1}}=F_{\text {eq }}+\frac{3}{4} F_{y}$ \\
& Since $F_{D_{2}}=F_{D_{4}}$, \\
& $F_{D_{1}}-F_{D_{2}}=F_{y}$ \\
& $F_{D_{3}}-F_{D_{2}}=F_{y}$ \\
& $F_{D_{1}}+2 F_{D_{2}}+F_{D_{3}}=F_{D_{\text {sum }}}$ \\
& Therefore, \\
& $F_{D_{2}}=F_{D_{4}}=F_{\text {eq }}-\frac{1}{4} F_{y}-\frac{1}{4} F_{z}$ \\
$F_{y}>0$ and $F_{z}>0$ & $F_{D_{1}}=F_{\text {eq }}+\frac{3}{4} F_{y}-\frac{1}{4} F_{z}$ \\
& $F_{D_{3}}=F_{\text {eq }}-\frac{1}{4} F_{y}+\frac{3}{4} F_{z}$ \\
&
\end{tabular}




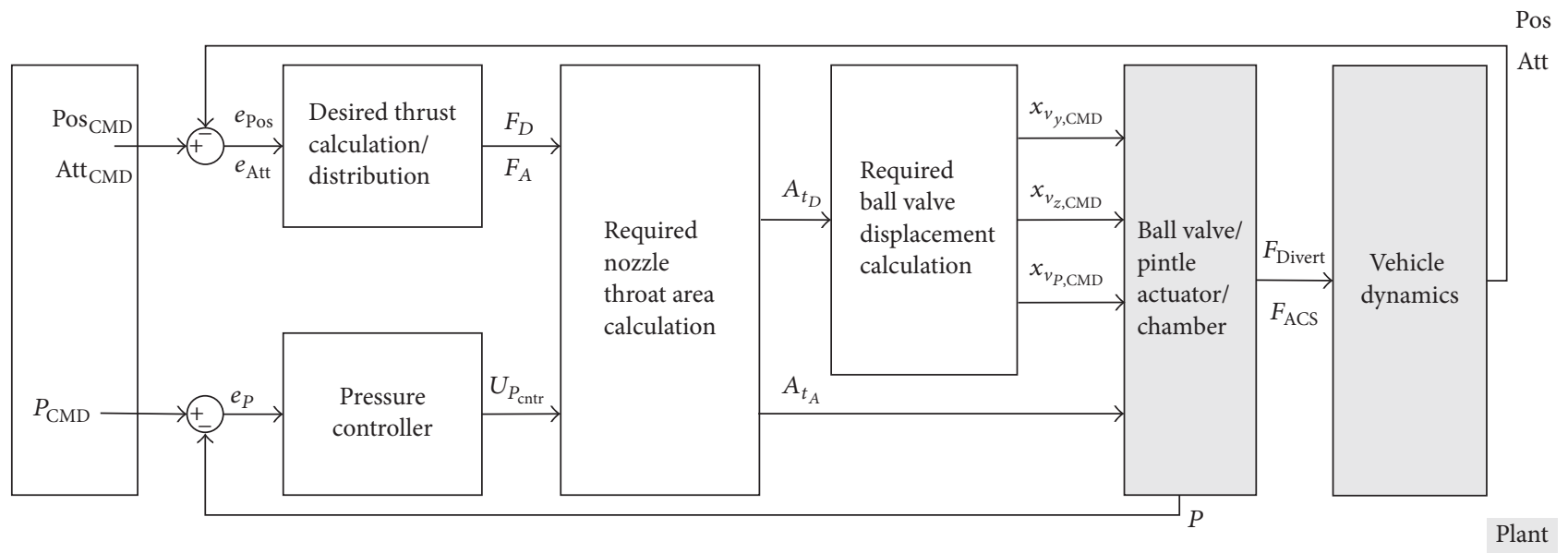

FIGURE 11: Control loop for the reduced actuator set.

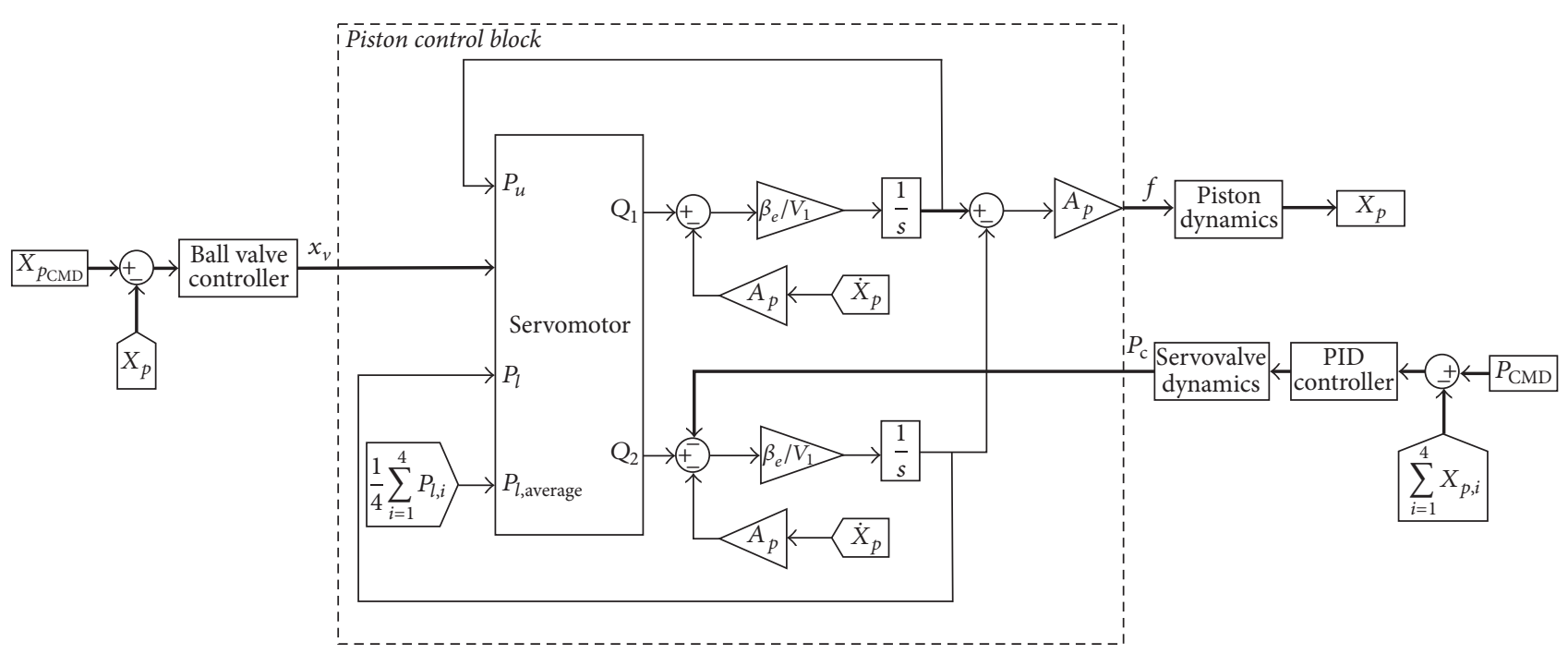

FIGURE 12: Simulated configuration for 1 nozzle.

Figure 11 shows the entire control loop with the proposed reduced actuator. From the desired DCS nozzle throat area, three valve commands can be achieved.

\section{Numerical Simulations}

The proposed actuator concept was verified using simulations. First, a numerical simulation was constructed with a single piston actuator as shown in Figure 12. $P_{u}$ and $P_{l}$ are the upper pressure and the pressure of the piston, respectively, and a pressure difference $\left(P_{u}-P_{l}\right)$ will create the pintle actuator displacement. This value is then fed back to the flow differential $\Delta Q$ calculation. For the valve voltage control, simple PID controller is used.

This can be extended to a simulation of four pistons using three actuators as Figure 13. Each piston will share the lower pressure $P_{l}$, which is averaged as $1 / 4 \times \sum_{i=1}^{4} P_{l, i}$ for the lower pressure of each piston, because they share the flow. The pressure control actuator is connected to the lower part, which controls each piston in the same direction by increasing or decreasing the amount of the incompressible fluid. Table 4 shows the simulation parameters.

Four simulation cases were considered here. The first simulation case is for when only one pintle actuator is moved. Because the volume of the incompressible fluid is conserved, the other three pintles are moved backward naturally when one of the pintles is controlled. The displacement of the backward maneuver in Figure 14 is equal to $1 / 3$ of the controlled pintle maneuver, which makes the sum of the displacement equal to zero. This means the thrust can be distributed automatically, with the pressure maintenance, by sharing incompressible fluid.

The second case involves the control of two pintle actuators, for the $y / z$-axis, respectively. There will be two remaining pintles which are not controlled for the $y / z$ axis. Similar to the first case, the remaining two pintles are moved backward, and the movement is a half of the control input sum, $\left(X_{p_{y}}+X_{p_{z}}\right) / 2$, respectively. Therefore, the 


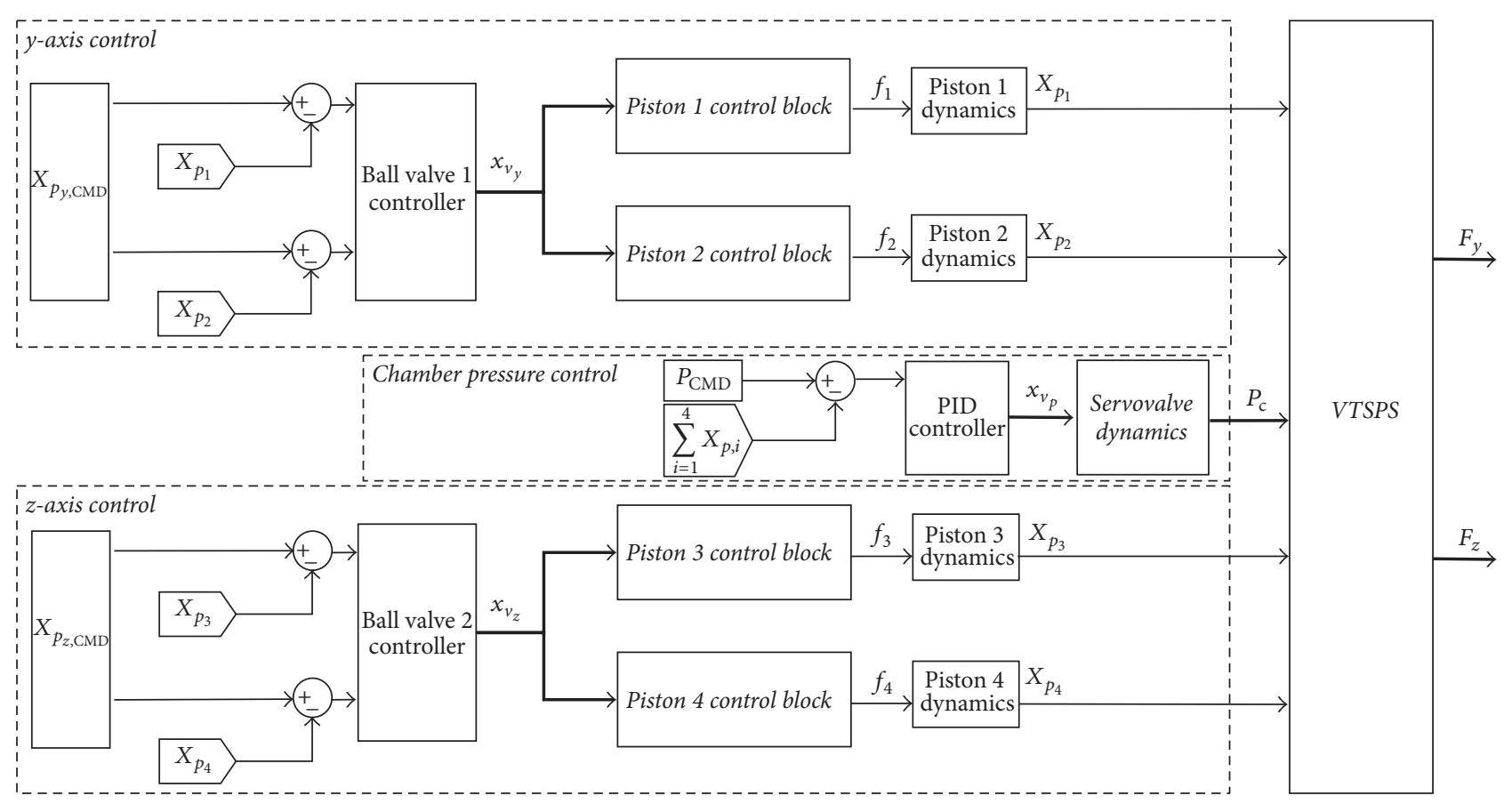

FIGURE 13: Simulation configuration for 4 nozzles.

TABLE 4: Simulation conditions.

\begin{tabular}{lc}
\hline Property & Values \\
\hline Amp gain $K_{\text {amp }}, \mathrm{Amp} / \mathrm{Vol}$ & 0.7407 \\
Servo valve gain $K_{\mathrm{sv}}, \mathrm{m} / \mathrm{A}$ & $4.8273 e-1$ \\
PID controller gain & \\
$K_{P}$ & 10 \\
$K_{D}$ & 5 \\
$K_{I}$ & 5 \\
Initial chamber volume, $\mathrm{m}^{3}$ & \\
$V_{1}$ & $32.25 e-3$ \\
$V_{2}$ & $161.25 e-2$ \\
Discharge coefficient $C_{d}$ & 0.611 \\
Fluid density $\rho, \mathrm{kg} / \mathrm{m}^{3}$ & 867 \\
Bulk modulus $\beta_{e}, \mathrm{~Pa}$ & $1.5 e 9$ \\
Supply pressure $P_{s}, \mathrm{~Pa}$ & $1 e 7$ \\
Return pressure $P_{r}, \mathrm{~Pa}$ & 0 \\
Valve inlet/outlet area $A, \mathrm{~m}^{2}$ & $2 e-6$ \\
Piston area $A_{p}, \mathrm{~m}^{2}$ & $645 e-6$ \\
\hline
\end{tabular}

sum of the displacement will also be zero. These results in Figure 15 indicate that thrust distribution can be achieved naturally by the incompressible fluid inside the piston without changing the chamber pressure. This show that the same control strategy could be obtained by controlling only two pintles, when the required thrust vector is not aligned to $y$ or $z$-axis.

The third case involves increasing the amount of incompressible fluid for pressure control only. In this case, all four of the pintles are moved with the same displacement as

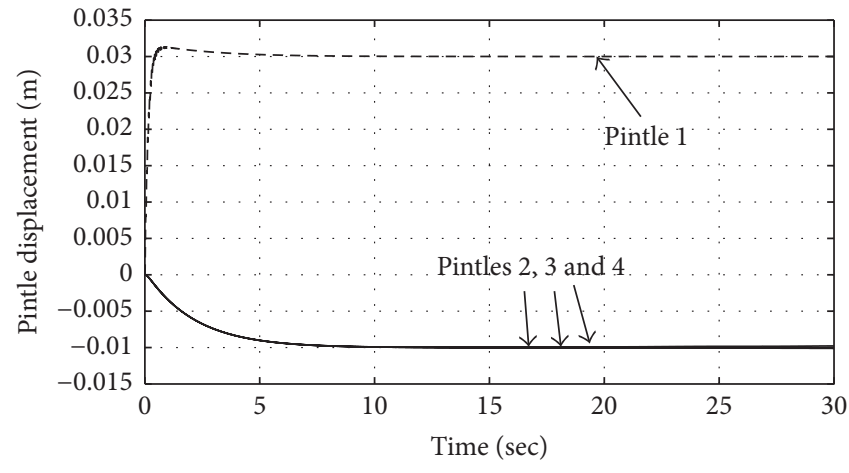

Figure 14: Simulation results, case (1).

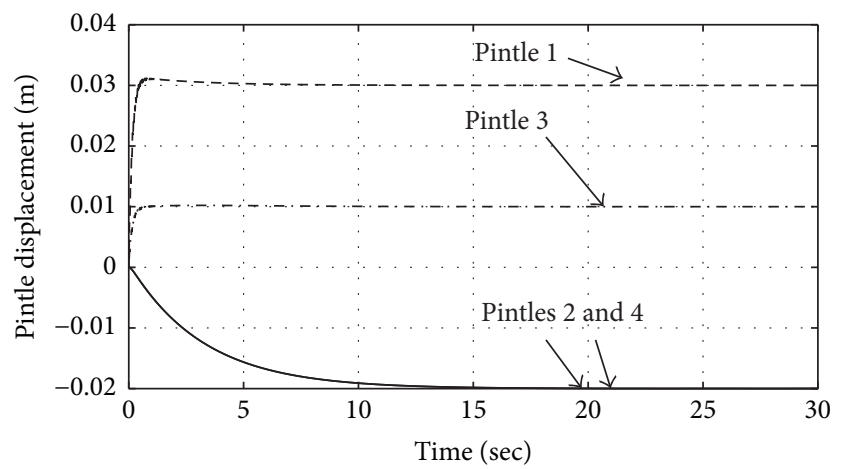

FIGURE 15: Simulation results, case (4).

Figure 16. Since the $+y$ and $-y$ pintles are moved equally, the thrust in the $y$-axis is eliminated and no net thrust will be generated. The same analysis can be performed for the $z$-axis. 


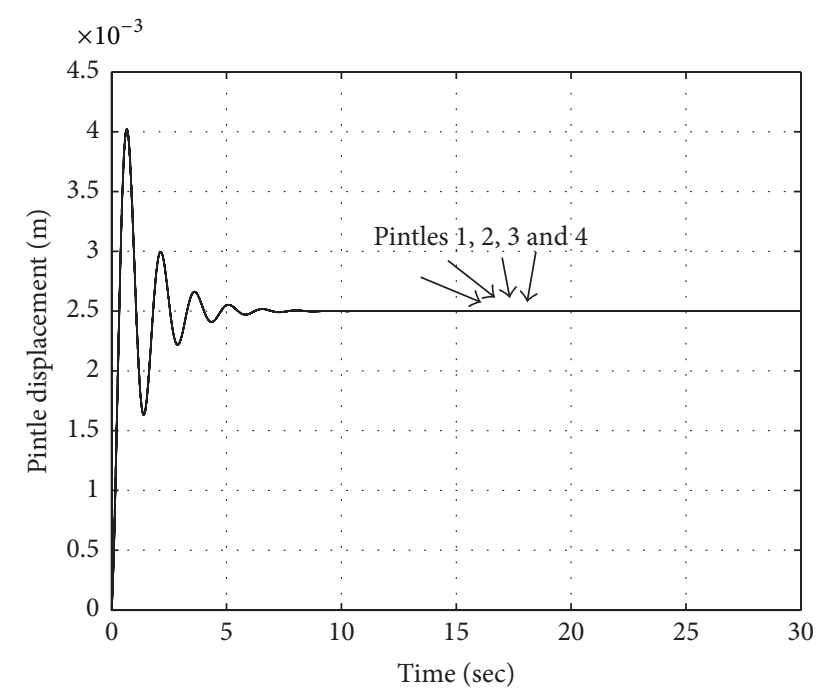

Figure 16: Simulation results, case (2).

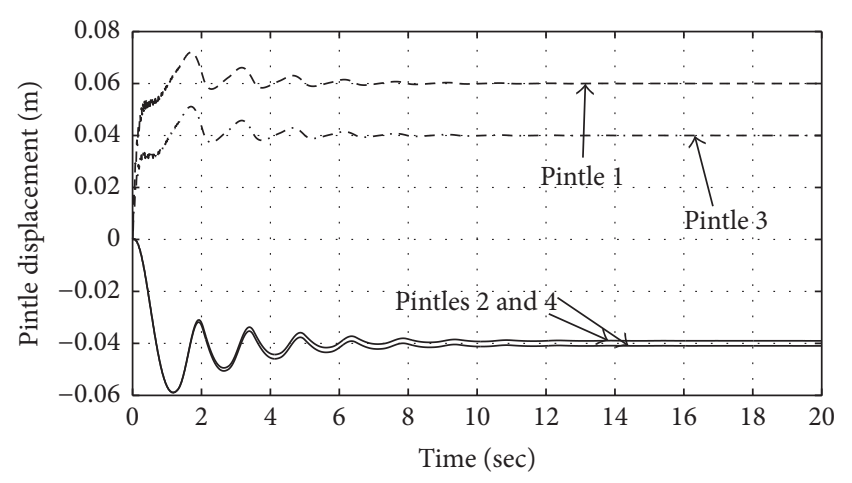

Figure 17: Simulation results, case (3).

Since all of the pintles are moved, this means the net nozzle throat area is changed, and there is no net thrust, and only the pressure control will be affected.

Figure 17 represents the final case, which is the sum of the previous cases from (1) to (3). One pintle is controlled for each $y / z$-axis, while the incompressible fluid is increased. Since the amount of fluid is changed, the net displacement will not be zero, which means the chamber pressure will be changed. Although there will be a pressure difference, the resultant net thrust will be the same as in case (2), since each pintle is moved equally, and the additional thrusts will vanish. This shows the thrust maneuvering can be achieved while changing the chamber pressure at the same time.

\section{Conclusion}

A novel actuator mechanism for a solid propulsion system with multiple nozzles was introduced. While conventional pintle actuators control each nozzle throat independently, and the number of actuators is equal to the number of nozzles, the proposed concept allows the number of actuators to be reduced. Because the actuators in the proposed design all share an incompressible fluid, the system both controls the pressure and distributes thrusts at the same time. Since the incompressible fluid volume is conserved, the uncontrolled pintles move reciprocally when one or two of the pintle actuators is moved. By increasing or decreasing the amount of incompressible fluid, the net nozzle throat area can be controlled and the chamber pressure will be changed as well. The performance of the proposed actuator mechanism was verified by simulations, and the results of those analyses showed that pressure maintenance as well as thrust allocation was achieved simultaneously. The efficiency of the achieved thrust distribution was identical to that reported for conventional actuators. These analyses were performed while assuming that the nozzle throat area change was linear with respect to the pintle actuator movement, and therefore cases in which the thrust distribution creates a more complex relationship between the pintle movement and the nozzle throat area should be studied further.

\section{Nomenclature}

\begin{tabular}{|c|c|}
\hline$C_{f}:$ & Thrust coefficient \\
\hline$A_{t}:$ & Throat area, $\mathrm{m}^{2}$ \\
\hline$F_{A_{i}}, F_{D_{i}}$ & $\begin{array}{l}\text { Thrust of the ith attitude/divert control } \\
\text { nozzle, } \mathrm{N}\end{array}$ \\
\hline$F_{\text {sys }}:$ & $\begin{array}{l}\text { Total system thrust generated under } \\
\text { chamber pressure control, } \mathrm{N}\end{array}$ \\
\hline$F_{D_{\text {sum }}}:$ & $\begin{array}{l}\text { Available total thrust after substituting the } \\
\text { attitude control system thrusts, } \mathrm{N}\end{array}$ \\
\hline$F_{\mathrm{eq}}:$ & Equivalent (null) thrust, $\mathrm{N}$ \\
\hline$F_{y}, F_{z}:$ & $y / z$-axis forces, $\mathrm{N}$ \\
\hline$F_{\phi}, F_{\theta}, F_{\psi}:$ & Roll, pitch, and yaw axis forces, $\mathrm{N}$ \\
\hline$\phi, \theta, \psi:$ & Roll, pitch, and yaw angles, deg \\
\hline$x_{v}:$ & Valve displacement, $\mathrm{m}$ \\
\hline$X_{p}:$ & Pintle (piston) displacement, $\mathrm{m}$ \\
\hline$f_{i}^{P}:$ & Force applied to $i$ th piston, N. \\
\hline
\end{tabular}

\section{Conflicts of Interest}

The authors declare that there are no conflicts of interest regarding the publication of this paper.

\section{Acknowledgments}

This work was supported by the Defense Acquisition Program Administration and Agency for Defense Development under the Contract no. UD110093CD. The authors truly appreciate their financial support.

\section{References}

[1] J. W. Morris, R. W. Calson, K. L. Peterson, and E. M. Reich, "Multiple pintle nozzle propulsion control system," U.S. Patent 5,456,425, 1995.

[2] W. Lee, Y. Eun, H. Bang, and H. Lee, "Efficient thrust distribution with adaptive pressure control for multinozzle solid propulsion system," Journal of Propulsion and Power, vol. 29, no. 6, pp. 1410-1419, 2013.

[3] J. L. Bergmans and R. Di Salvo, "Solid rocket motor control: theoretical motivation and experimental demonstration," in 
Proceedings of the 39th AIAA/ASME/SAE/ASEE Joint Propulsion Conference and Exhibit, AIAA Paper 2003-4968, Huntsville, Ala, USA, July 2003.

[4] H.-L. Choi and J.-T. Lim, "Feedback linearisation of timevarying nonlinear systems via time-varying diffeomorphism," IEE Proceedings: Control Theory and Applications, vol. 150, no. 3, pp. 279-284, 2003.

[5] R. Marino and P. Tomei, "Adaptive output feedback tracking for nonlinear systems with time-varying parameters," in Proceedings of the 36th IEEE Conference on Decision and Control, pp. 2483-2488, San Diego, Cali, USA, December 1997.

[6] Y. Diao and K. M. Passino, "Stable adaptive control of feedback linearizable time-varying non-linear systems with application to fault-tolerant engine control," International Journal of Control, vol. 77, no. 17, pp. 1463-1480, 2004.

[7] G. Young, H. A. Bruck, and S. Gowrisankaran, "Modeling of rocket motor ballistics for functionally graded propellants," in Proceedings of the 39th JANNAF Combustion Meeting, Colorado Springs, Colo, USA, December 2003.

[8] G. P. Sutton and O. Biblarz, Rocket Propulsion Elements, Wiley, New York, NY, USA, 2001. 


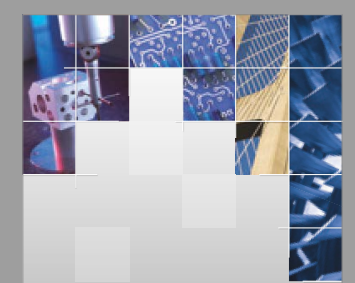

\section{Enfincering}
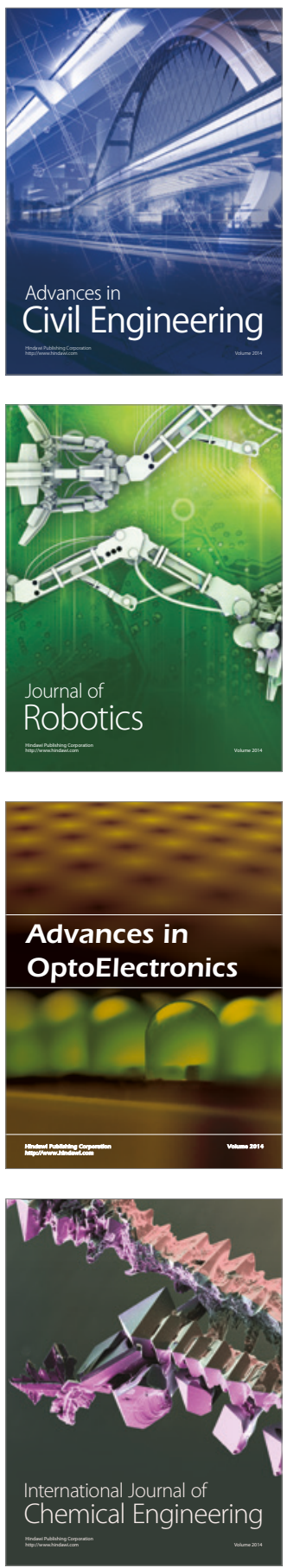

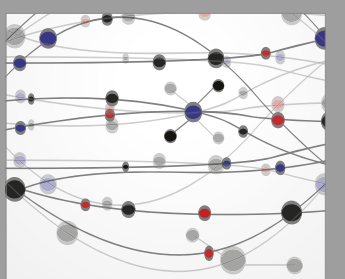

The Scientific World Journal

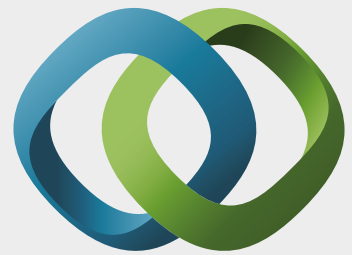

\section{Hindawi}

Submit your manuscripts at

https://www.hindawi.com
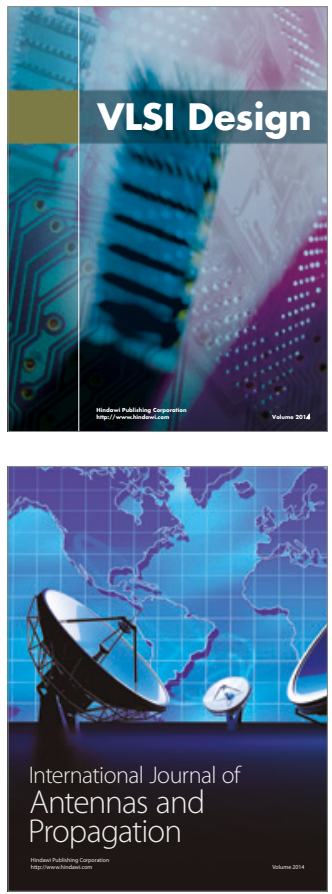

\section{Rotating}

Machinery
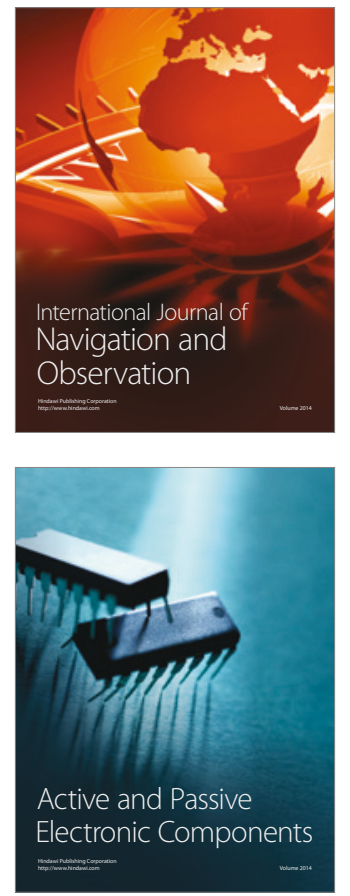
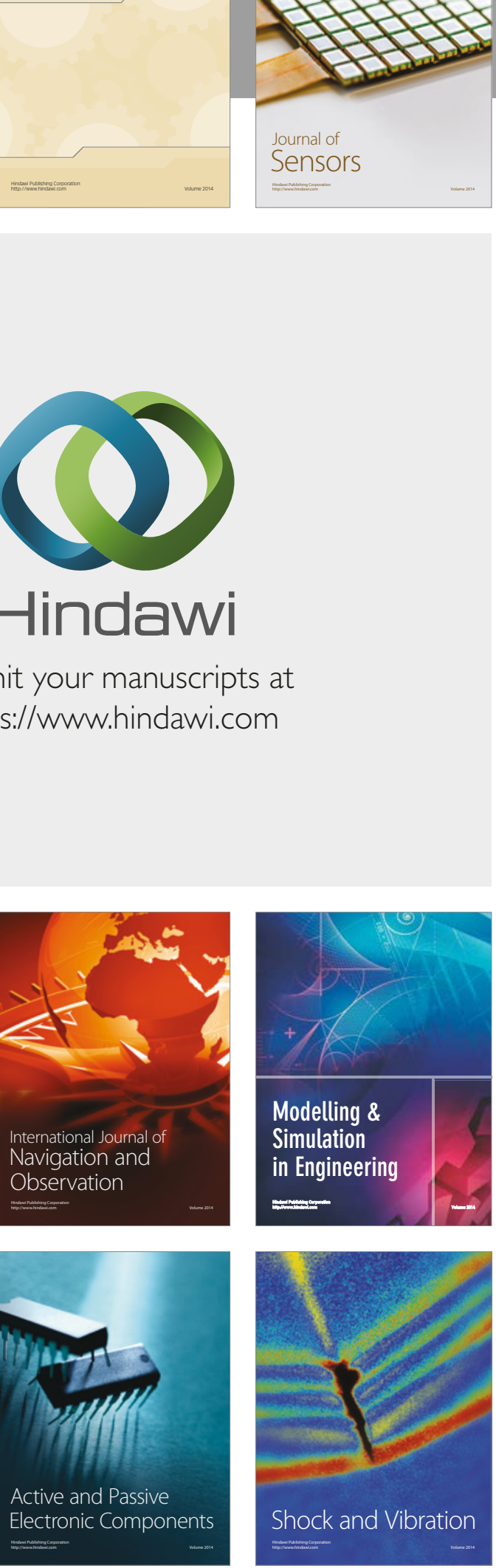
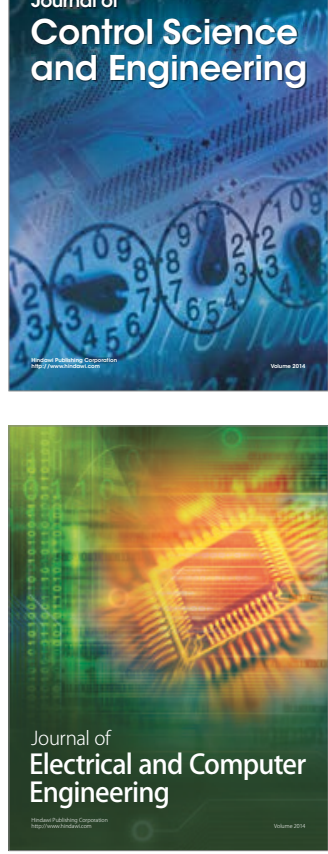

Distributed

Journal of

Control Science

and Engineering
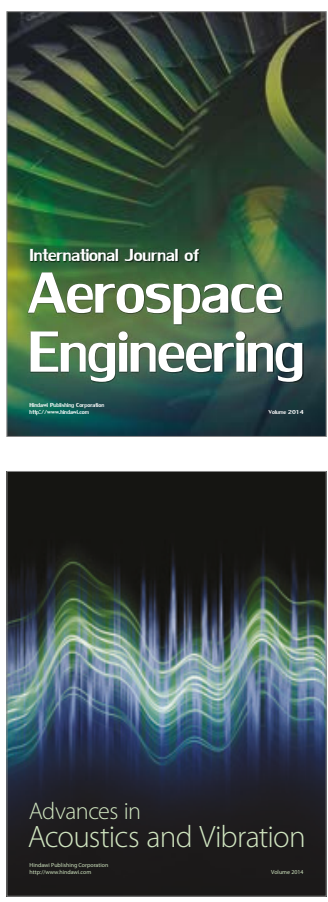

Sensor Networks 